\title{
Thermal Stability and Microstructure of Nanometric 2024 Aluminum Alloy Powder Obtained by Cryogenic Milling and Spark Plasma Sintering
}

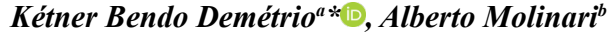 \\ ${ }^{a}$ Programa de Pós-Graduação em Ciência e Engenharia de Materiais - PPGCEM, Universidade do \\ Extremo Sul Catarinense, Av. Universitária, 1105, Bairro Universitário, 88806-000, Criciuma, SC, \\ Brasil \\ ${ }^{b}$ Dipartimento di Ingegneria dei Materiali, Universita degli Studi di Trento, Via Mesiano 77, 38100, \\ Povo, Trento, Italia
}

Received: March 09, 2018; Revised: June 07, 2018; Accepted: August 05, 2018

\begin{abstract}
Metals and nanocrystalline alloy powders can be produced by high-energy milling and be consolidated by sintering techniques; the use of relatively low sintering temperatures maintains nanometric grains by avoiding grain growth. In the present study, 2024 aluminum alloy powders were produced by milling at cryogenic temperatures (cryomilling) and consolidation using spark plasma sintering (SPS). The thermal stability and microstructure of the nanometric $2024 \mathrm{Al}$ alloy powder produced by cryomilling were analyzed. The milled powder was degassed to improve its sintering behavior and avoid the presence of pores in the final sintered piece. When the material was consolidated by SPS at a temperature of $525^{\circ} \mathrm{C}$ and under a pressure of $60 \mathrm{MPa}$, the resulting alloy density was $98 \%$ and an ultra-fine grained (100-300 $\mathrm{nm}) /$ micrometric microstructure. The hardness and microhardness of the milled degassed sintered samples showed values superior to atomized samples. The material also presented nanopores in the grain boundaries, very fine precipitates of $\mathrm{AIN}$, rounded $\theta$ phases $\left(\mathrm{Al}_{2} \mathrm{Cu}\right)$, and elongated $\mathrm{S}$ phases $\left(\mathrm{Al}_{2} \mathrm{CuMg}\right)$.
\end{abstract}

Keywords: 2024 Al alloy, cryomilling, SPS, thermal stability, characterization.

\section{Introduction}

Aluminum alloys have a low specific weight, making them highly interesting for structural applications, such as those in the civil, metallurgical, and aeronautical industries. While their mechanical properties are lower than those of steel, structural refinement (limiting the grain size of the materials) extends their suitability to applications that require, e.g. excellent mechanical resistance ${ }^{1}$. Nanostructured metals (with grain sizes of 1-200 nm) and ultra-fine grained (UFG) materials (with grain sizes between 200 and $500 \mathrm{~nm}$ ) are of interest as they demonstrate unique combinations of physical and mechanical properties.

It has been demonstrated that nanostructured $\mathrm{Al}$ alloys can be obtained using high-energy milling techniques ${ }^{2,3}$. During milling, the grain size is determined by the balance between the recovery and formation of defects that arise due to severe plastic deformation ${ }^{4}$. Face-centered cubic (FCC) materials, such as $\mathrm{Al}$ and its alloys, are quite ductile; hence, it is difficult to reduce the crystallite size by mechanical milling. The opposite behavior is observed for body-centered cubic (BCC) and hexagonal close-packed (HCP) metals due to an accumulation of defects during milling and rapid recovery kinetics ${ }^{5,6}$. Cryogenic milling is a possible alternative to high-energy milling, where the powders are milled at very low temperatures, e.g. milling in liquid nitrogen at $-185^{\circ} \mathrm{C}^{2,7}$.

"e-mail: ketnerbd@gmail.com
Cryogenic milling techniques can achieve nanostructured alloys through severe plastic deformation of the material during this process $^{1}$. Due to the low temperature, cryomilling suppresses or limits the recovery and recrystallization of grains, which quickly creates a finer grain structure compared to other methods $^{1,8}$. In addition, cryogenic milling does not require the use of a process control agent that can contaminate the powder with carbon and oxygen, for example ${ }^{2}$.

The thermal stability of the nanostructure is a very important factor for preserving its properties and depends on the balance between the driving and resistance forces inside the grains. It is known that smaller grain sizes have a higher tendency for grain growth ${ }^{1,8}$. In most cases, the thermal stability of a nanostructure depends on the reticular defects present inside the grains, and on the particles surfaces, e.g. nitrides and oxides precipitated in the grain boundaries ${ }^{9-11}$. It is very important to obtain a balance between the grain size and the thermal stability of the material to prevent grain growth during sintering. In addition, very fine $(<200 \mathrm{~nm})$ powder particles are highly reactive with oxygen and sintering becomes difficult due to the oxide layers formed on the surfaces.

Dense nanomaterials can be produced using various powder metallurgy techniques, such as hot isostatic pressure, dynamic consolidation, hot extrusion, and spark plasma sintering (SPS) ${ }^{12,13}$. These processes can effectively achieve completely dense materials ${ }^{12-16}$. SPS is an innovative technology that has great potential due to the lower temperature and 
shorter sintering time compared to other techniques ${ }^{17-20}$. In this process, an electric current generates sparks that pass through the powder particles, resulting in efficient and localized high-temperature heating. Al powders are difficult to sinter due to the oxide layer formed on their surfaces; this layer needs to be broken to allow the particle sintering ${ }^{17}$. SPS has shown to be effective and efficient for producing $\mathrm{Al}^{17,21}$ and iron alloys ${ }^{22}$ from nanostructured powders. A bimodal microstructure can be formed during sintering due to localized overheating generated by the sparks and the low thermal stability of the material ${ }^{12}$. Such a bimodal microstructure produces high ductility ${ }^{23-25}$, which is the most critical characteristic of nanostructured metals. In summary, UFG/nanometric crystallites result in materials with high mechanical resistance and the micrometric grains provide increased ductility. Another strategy for improving the ductility is to apply high rates of deformation at low temperatures, which results in an accumulation of defects within the UFG/nanometric structure, resulting in more effective deformation hardening ${ }^{26}$.

This study demonstrates the processing of nanometric $2024 \mathrm{Al}$ alloy powders using cryogenic milling and the production of ultra-fine/micrometric grains of dense material sintered by SPS. The physical and chemical properties of these powders were analyzed, along with their thermal stability. In addition, the sintering behavior of the powders processed using SPS was investigated. The effect of degassing the powders before sintering on the microstructure, hardness, and microhardness was also investigated.

\section{Experimental Procedure}

\subsection{Cryogenic milling}

The powders used were produced by Ecka Granules (Germany) using a gas atomization method. The chemical composition of the 2024 aluminum alloy used was $4.0 \mathrm{wt} \%$ $\mathrm{Cu}, 1.5 \mathrm{wt} \% \mathrm{Mg}, 0.6 \mathrm{wt} \% \mathrm{Mn}$, and $\mathrm{Al}$ (balance). The 2024 Al alloy powder was processed by cryomilling in liquid nitrogen without the use of a process control agent (PCA; such as methanol, stearic acid and/or paraffin compounds), which is normally used as a lubricant in milling process to prevent the formation of agglomerates. The milling was performed in a container with stainless steel milling balls. The ball-to-powder ratio was 32:1 (corresponding to the highenergy regime). In order to improve the metal sinterability by eliminating humidity and gases, the milled powders were degassed at two different temperatures, either $250^{\circ} \mathrm{C}$ or $350^{\circ} \mathrm{C}$, for $20 \mathrm{~h}$ in a tubular oven under high vacuum $\left(10^{-3}\right.$ $\mathrm{Pa})$. To investigate the grain size distribution of the milled powders, optical microscopy images from a Zeiss LOM microscope equipped with a camera (Leica DC300 ${ }^{\circledR}$ ) were analyzed using image analysis software (Image $\mathbf{J}^{\circledR}$ version 1.51r). Sieving was performed separately for each mesh size $(<25,25-45,45-90,90-120$, and $>120 \mu \mathrm{m})$ for the asreceived and milled powders. The cryomilled powders were analyzed by X-ray diffraction (XRD) where the diffraction patterns were recorded using $\mathrm{Cu} \mathrm{K} \alpha$ radiation $(\lambda=1.5418)$. Scanning electron microscopy (SEM; Philips XL $30^{\circledR}$ and a Supra 40 ZEISS with a GEMINI ${ }^{\circledR}$ column) was used to observe the morphology of the metal particles before and after milling. Transmission electron microscopy (TEM; Philips CM12) was used to identify precipitates in the material after sintering. Identification of the precipitates was made via indexing selected-area electron diffraction (SAED) patterns. Differential scanning calorimetry (DSC; Perkin-Elmer DSC7-TAC7/7 Instrument Controller) under argon at $20 \mathrm{ml} / \mathrm{min}$ fluxing atmosphere was undertaken on the powders to investigate their thermal stability, where temperature cycling was performed on the atomized and milled powders at different heating rates between 10 and $40{ }^{\circ} \mathrm{C} / \mathrm{min}$.

\subsection{Spark plasma sintering}

SPS was performed using a Dr. Sinter $1050^{\circledR}$ SPS system (Sumitomo Coal \& Mining Ltd.) with a graphite die. During sintering, the material was pressed into the matrix and the plasma sparks were applied to the sample. The graphite used in the matrix and punches is a conducting material that facilitates localized sintering. The cylindrical samples (diameter of $3 \mathrm{~mm}$ and height of $6 \mathrm{~mm}$ ) were sintered at temperatures of 350 or $525^{\circ} \mathrm{C}$ with an applied pressure of 60 $\mathrm{MPa}$, holding time of $1 \mathrm{~min}$, and free cooling. The geometric density of the samples was calculated using Archimedes' method. The microhardness was measured using a Vickers Paar MHT- $4{ }^{\circledR}$ micro-indenter and load of $0.05 \mathrm{~N}$ for $10 \mathrm{~s}$ holding time and the hardness was measured using the Brinell method, with an Emco Test Automatic M4U 025 ${ }^{\circledR}$ instrument with a load of $62.5 \mathrm{~N}$. The nitrogen and oxygen contents were analyzed by chemical analyses using a LECO TC400 analyser. The same SEM and TEM instruments were used to characterize the microstructure of the sintered samples, where identification of the precipitates was undertaken using a built-in energy-dispersive X-ray spectroscopy (EDS) system. The diffraction pattern was collected using a $\mathrm{Cu} \mathrm{K} \alpha$ $(\lambda=1.5418)$ source and an image plate detector over the $2 \theta$ range from $10^{\circ}$ to $100^{\circ}$ in reflection geometry.

\section{Results and Discussion}

\subsection{Cryomilled powder morphology}

Figure 1 shows the crystallite size as functions of milling time and microstrain. The size of the crystallites decreased and the internal deformation increased with increasing milling time, as expected ${ }^{27}$. After $30 \mathrm{~h}$ of high-energy milling, the grain size was $21 \mathrm{~nm}$ and the microstrain was 0.31 . 


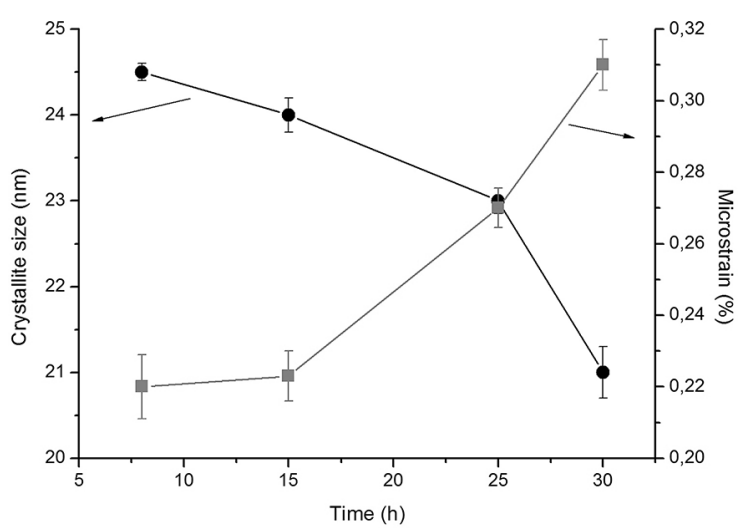

Figure 1. Size of the crystallites and microstrain in the powder as functions of milling time obtained by XRD Analysis.

Figure 2 shows the particle size distribution and morphology of the as-received atomized and milled powders. Figure 2(a) shows that the atomized powder consisted of particles with a spherical shape, where approximately $60 \%$ of the particles were smaller than $25 \mu \mathrm{m}$. The milled particles were approximately spherical. Figures 2(b) and (c) show that the cryomilled particles were in the form of flakes, indicating that the milling process had not reached its final stage (producing rounded particles). The size distributions showed narrow peaks, where most of the particles were below $30 \mu \mathrm{m}$ after $8 \mathrm{~h}$ and below $15 \mu \mathrm{m}$ after $25 \mathrm{~h}$ of milling. Figure 3 shows TEM images of powder particles milled for $8 \mathrm{~h}$; bright field (BF), dark field (DF), and SAED images are shown. These images show nanometric grains with diameters of about 20-100 nm.

\subsection{Thermal stability}

It is well known that the thermal stability of a nanostructured material depends on the balance between the driving force, due to the surface energy of the grain boundary, and resistance force, which reduces the mobility of the grain boundary ${ }^{10,11,28,29}$. The driving force for the growth of the grain $\Delta \mathrm{G}$ is the excess of Gibbs free energy related to the surface of the grain boundary, given by equation $(1)^{29}$.

$$
\Delta G=\gamma \Delta S=\frac{3.3 \gamma}{D}
$$

where $\gamma$ is the specific energy of the grain boundary (from 0.18 to $0.32 \mathrm{~J} / \mathrm{m}^{2}$ for $\mathrm{Al}$ alloys $\left.{ }^{30}\right), \Delta \mathrm{S}$ is the specific surface area of the grain boundary $\left(\mathrm{m}^{2} / \mathrm{m}^{3}\right)$, and $\mathrm{D}$ is the average grain size $(m)$. From the calorimetric point of view, once $\Delta \mathrm{G}$ increases by decreasing the average size of the grain, the smaller grains have a greater tendency for grain growth. The mobility of the grain boundaries is reduced by the presence of neighboring geometric dislocations, which explains the residual deformation accumulated during milling ${ }^{31}$.

The average microstrain and the grain size (obtained by XRD analyses) were used to calculate the dislocation density, using equation (2) ${ }^{32}$.

$$
\rho=\left(\rho_{D} \rho_{S}\right)^{1 / 2}=\frac{2 \sqrt{3}\left(\varepsilon^{2}\right)^{\frac{1}{2}}}{D b}
$$

where $\rho$ is the dislocation density $\left(\mathrm{m}^{-2}\right), \rho D$ is the dislocation density due to the size of the grain $\left(\mathrm{m}^{-2}\right), \rho S$ is the dislocation density due to the microstrain $\left(\mathrm{m}^{-2}\right), D$ is the average grain size $(\mathrm{m}),<\varepsilon 2>^{1 / 2}$ is the root mean square lattice microstrain (\%) and $b$ is the Bürger's vector modulus $\left(0.286 \times 10^{-9} \mathrm{~m}\right)^{32}$. The dislocation densities of samples in this study depended on the milling times and are shown in Table 1.

When the grain boundary is described as an arrangement of defects, the resistance offered by the accumulated deformations among crystallites and inside the grains can be expressed as the stress required to move these defects 9 . From the micromechanical point of view, it can be assumed that the movement of a grain boundary is due to the driving stress $\tau l$ resulting from the driving force of grain growth, which is opposed by the resistance stress $\tau 2$ which is the drag force induced by defects in the deformed regions; grain growth can occur if $\tau l$ is higher than $\tau 2^{33}$. The driving stress is expressed by equation (3) .

$$
\tau_{2}=\phi \Delta G=\phi \gamma \Delta S=\frac{3.30 \gamma}{D}
$$

where $\phi$ is a constant assumed equal to unity and described in equation (1) and (2).

The resistance stress is given by equation (4) ${ }^{9}$.

$$
\tau_{2}=\frac{G b \rho^{\frac{1}{2}}}{8 \pi(1-v)}
$$

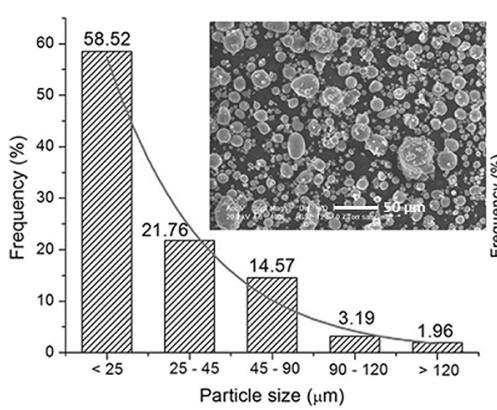

(a)

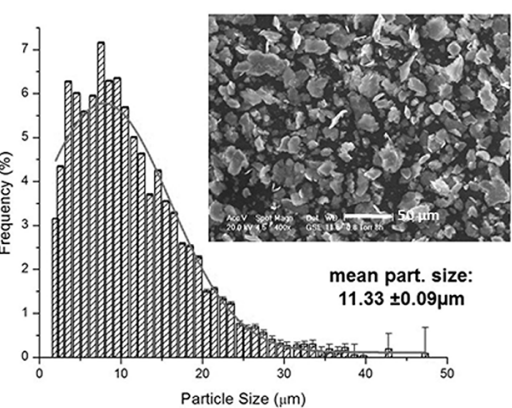

(b)

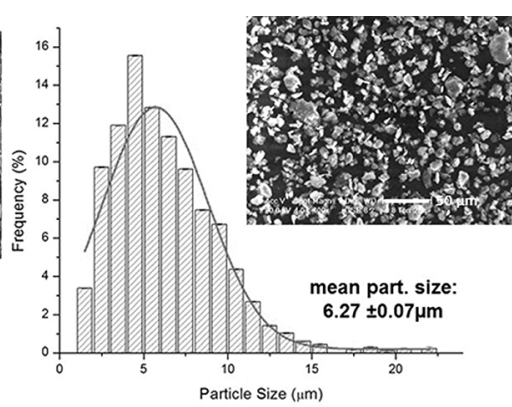

(c)

Figure 2. Size distribution and SEM images of the powders (a) as-received atomized powder, and powders milled for (b) $8 \mathrm{~h}$ and (c) $25 \mathrm{~h}$. 


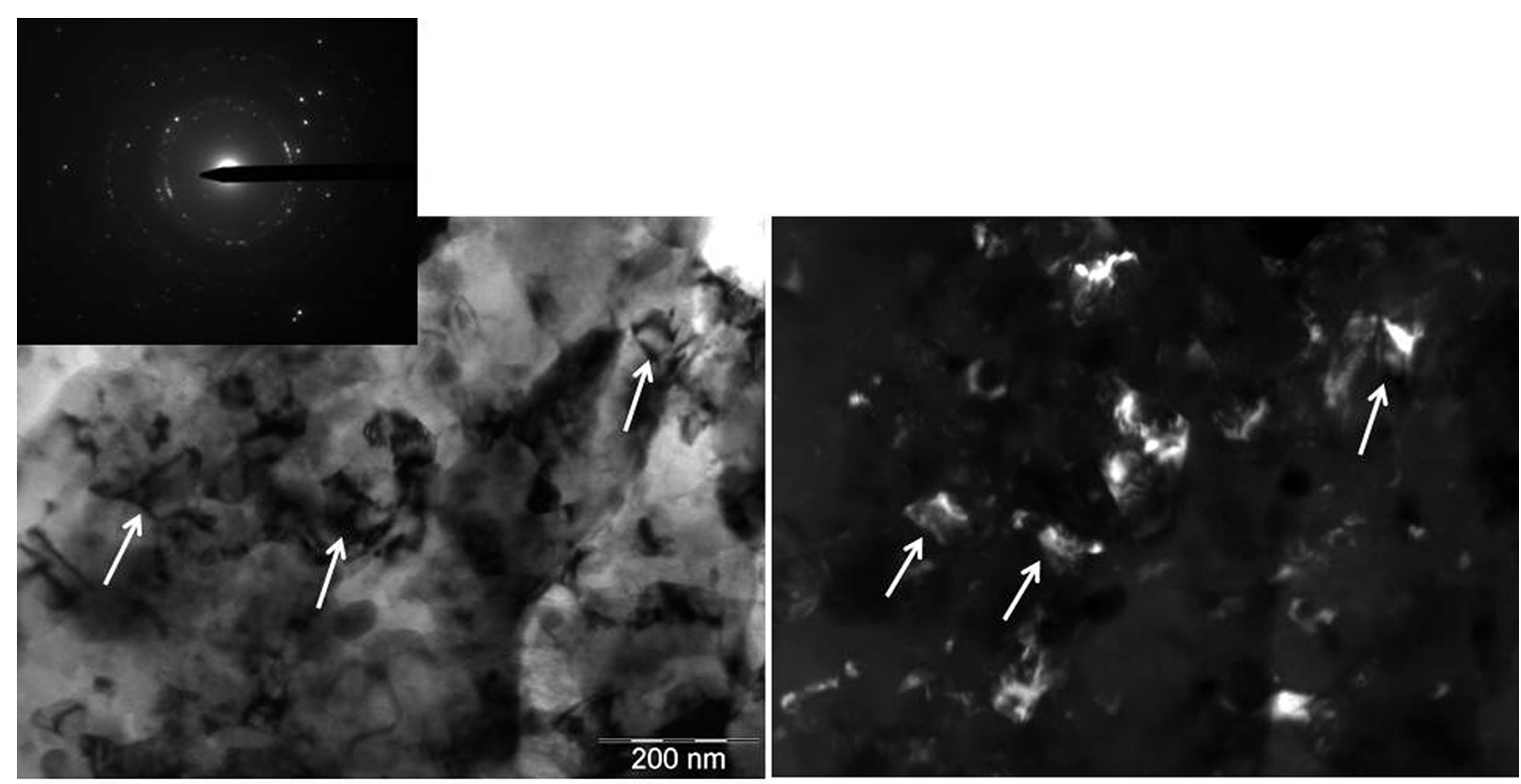

Figure 3. (a) Bright field (BF) and (b) dark field (DF) TEM micrographs of powder milled for $8 \mathrm{~h}$. The nanoparticles are indicated by arrows. The inset shows a SAED pattern.

Table 1. Dislocation densities of high energy milled powder calculated using equation 2 .

\begin{tabular}{lccc}
\hline Milling time (h) & Particle size $(\boldsymbol{\mu m})$ & $>\boldsymbol{D}(\mathbf{n m})$ & $\boldsymbol{\rho}\left(\mathbf{m}^{-2}\right)$ \\
\hline 8 & $<30$ & 24.5 & $1.15 \times 10^{15}$ \\
25 & $<15$ & 23 & $1.80 \times 10^{15}$ \\
\hline
\end{tabular}

where $G$ is the shear modulus $\left(0.262 \times 10^{11} \mathrm{~Pa}\right)$ and $v$ is the Poisson coefficient (0.345). The driving and resistance stresses in the grain boundary of samples are listed in Table 2.

The driving stress was calculated using an average value of specific energy in the grain boundary as reported in the literature $\left(0.25 \mathrm{~J} / \mathrm{m}^{2}\right)^{30}$. The stress decreased with increasing crystallite size; however, $\tau 1$ was always greater than $\tau 2$, meaning that the thermal stability of these nanostructured powders was quite low. Hence, rapid grain growth during heating was expected. The ball-to-powder ratio of 32:1 was considered effective for producing a nanostructured 2024 Al alloy powder. The particles were extremely fine $(<15$ $\mu \mathrm{m})$ after $25 \mathrm{~h}$ of milling, since the aluminum is extremely reactive with oxygen as finer the particles. In addition, the $8 \mathrm{~h}$ cryomilled powder showed grain sizes close to the minimum grain size $\left(\mathrm{d}_{\min }\right)$ of around $24.5 \mathrm{~nm}$. The grain sizes, microstrains, and dislocation densities were similar for powders milled for $8 \mathrm{~h}$ or $25 \mathrm{~h}$. Therefore, the tests were performed only on the powder milled for $8 \mathrm{~h}$.
The DSC curves of the powders (figure 4) showed an endothermic peak (I) at $250-330^{\circ} \mathrm{C}$ for the atomized powders and at $110-240{ }^{\circ} \mathrm{C}$ for the milled powders. This region represents the dissolution of Guinier-Preston (GP) zones formed during the heat treatment ${ }^{34,35}$. The precipitation of the GP zones was present for both powders. Wang et al. ${ }^{36}$ assigned the large subsequent exothermic peaks (II and III) at $330-420^{\circ} \mathrm{C}$ for the atomized powder and $250-420^{\circ} \mathrm{C}$ for the milled powders to the precipitation of coherent $\theta^{\prime \prime}$ and semi-coherent $\theta^{\prime} / \mathrm{S}^{\prime}$ phases. According to Badini et al. ${ }^{34}$ two different ageing sequences can occur separately or concurrently depending on the $\mathrm{Cu}$ content and the $\mathrm{Cu}: \mathrm{Mg}$ ratio in the alloy. During artificial ageing of these as-quenched alloys Al-Cu and/or Al-Cu-Mg metastable phases take place. If the ageing treatment is carried out for a long time, the stable incoherent $\mathrm{Al}_{2} \mathrm{Cu}(\theta)$ and/or $\mathrm{Al}_{2} \mathrm{CuMg}(\mathrm{S})$ phases occur according to the isothermal section at the ageing temperature of the $\mathrm{Al}-\mathrm{Cu}-\mathrm{Mg}$ phase diagram. The decomposition of supersaturated $\mathrm{Al}-\mathrm{Cu}$ solid solution results in the formation of the phases: GP zone $\rightarrow \theta " \rightarrow \theta ' \rightarrow \theta\left(\mathrm{Al}_{2} \mathrm{Cu}\right)$. The formation of a supersaturated $\mathrm{Al}-\mathrm{Cu}-\mathrm{Mg}$ solid solution leads to the following precipitation

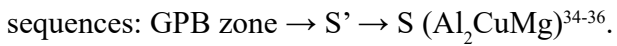

Endothermic peaks (IV and V) at $470-500{ }^{\circ} \mathrm{C}$ and 420 $490{ }^{\circ} \mathrm{C}$, respectively, for the atomized powder and milled powders were observed. The atomized powder showed two

Table 2. Driving stress $\left(\tau_{1}\right)$ and resistance stress $\left(\tau_{2}\right)$ values in the grain boundaries.

\begin{tabular}{lccccc}
\hline $\begin{array}{c}\text { Milling time } \\
(\mathbf{h})\end{array}$ & Particle size $(\boldsymbol{\mu m})$ & $\boldsymbol{D}(\mathbf{n m})$ & $\boldsymbol{\tau}_{1}\left(\mathbf{N} / \mathbf{m m}^{-2}\right)$ & $\boldsymbol{\tau}_{2}\left(\mathbf{N} / \mathbf{m m}^{-2}\right)$ & $\boldsymbol{\tau}_{1}-\boldsymbol{\tau}_{2}\left(\mathbf{N} / \mathbf{m m}^{-2}\right)$ \\
\hline 8 & $<30$ & 24.5 & $3.41 \times 10^{7}$ & $1.54 \times 10^{7}$ & $1.87 \times 10^{7}$ \\
25 & $<15$ & 23 & $3.63 \times 10^{7}$ & $1.93 \times 10^{7}$ & $1.70 \times 10^{7}$ \\
\hline
\end{tabular}




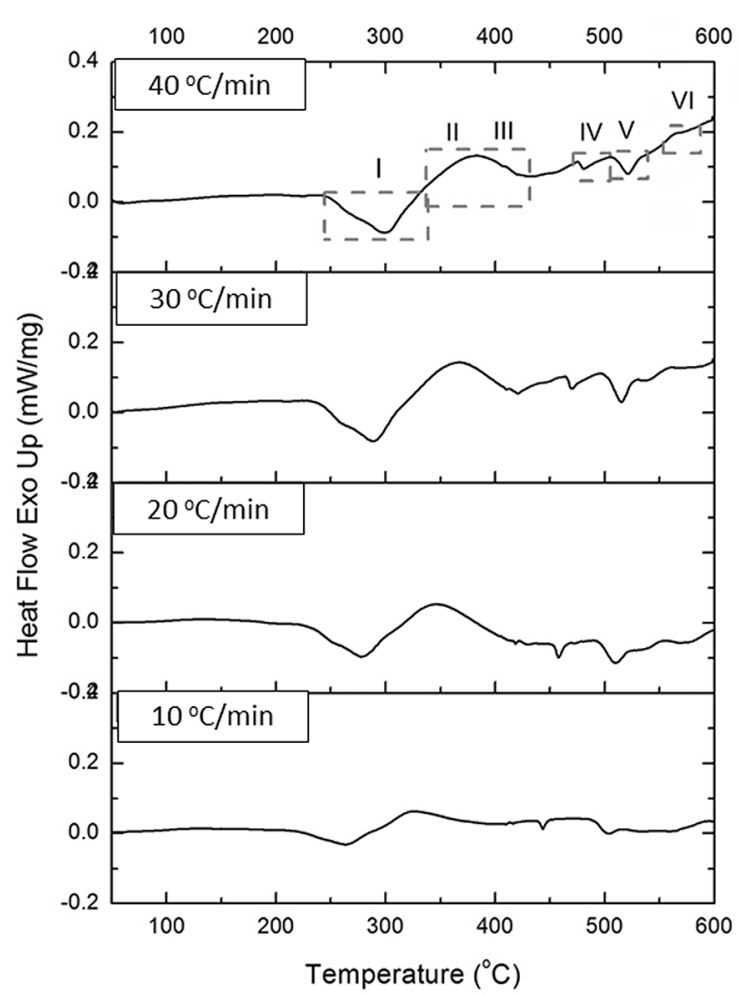

(a)

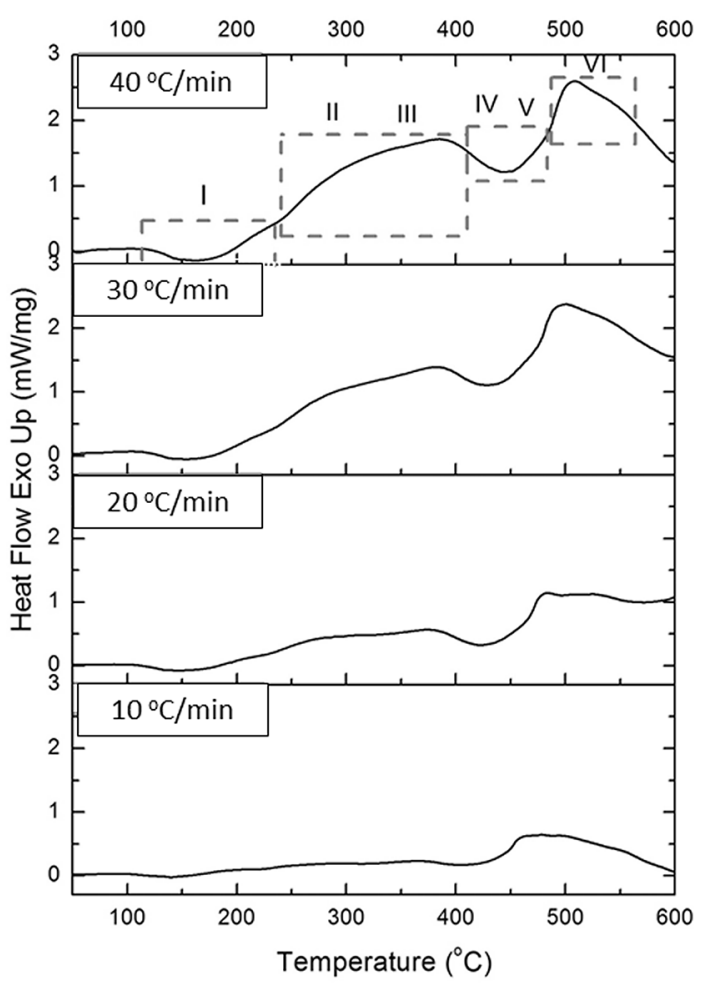

(b)

Figure 4. DSC curves for (a) as-received atomized powder and (b) powder milled for $8 \mathrm{~h}$, measured using heating rates of 10, 20, 30, and $40^{\circ} \mathrm{C} / \mathrm{min}$.

endothermic peaks, while the milled power had only one peak (where the two peaks were probably overlapping). Such endothermic peaks are related to the dissolution of the $\theta^{\prime \prime}$ and $\theta^{\prime} / \mathrm{S}^{\prime}$ phases ${ }^{37}$. The highest temperature exothermic peak (VI) was observed at $550-570{ }^{\circ} \mathrm{C}$ for the atomized powder and at $490-550^{\circ} \mathrm{C}$ for the milled powder and is associated with the precipitation of the incoherent $\theta / S$ phase and may be related to structural relaxation and/or grain growth ${ }^{35,38}$. The DSC curve of the milled powder showed a large exothermic peak over the studied temperature range, attributed to the deformation recovery and grain growth during heating. An investigation of the transformations involving GP zones and precipitates was published by Badini et al. ${ }^{34}$ for an $\mathrm{Al}$ alloy reinforced with $\mathrm{SiC}$. Such transformations were attributed to the tension accumulated in the interface between the particle and metal matrix. The same effect is thought to be relevant here and could be used to explain the changes in the DSC peaks of the nanostructured powder as the milled powder had a large deformation in the crystalline lattice due to the nanostructure produced during milling. The milling process introduces a high density of dislocations into the material, which causes a large quantity of preferential nucleation sites for precipitation; in addition, precipitation was accelerated by a reduction in the energy barrier for nucleation and the activation energy of precipitate formation. The DSC curves showed that the introduction of defects by the milling process did not alter the sequence of precipitation during heating, but resulted in faster kinetics ${ }^{36}$.

\subsection{Powder densification}

Figure 5 shows the sintering curves (displacement rate and vacuum pressure as functions of temperature) for the non-degassed powder milled for $8 \mathrm{~h}$ and then sintered at $525{ }^{\circ} \mathrm{C}$ under $60 \mathrm{MPa}$ of pressure. The displacement rate presented two peaks; the first peak, around $140{ }^{\circ} \mathrm{C}$, corresponded to the rearrangement of particles and the removal of gas adsorbed on the surface of the particles during heating (in situ degassing of the powder), at the same temperature found in the vacuum curve. At this point, the samples did not show evidence of sintering, consistent with results presented in the literature ${ }^{39}$. The second peak, around $260^{\circ} \mathrm{C}$, corresponded to the densification process, where the powder was compacted. The formation of necks between the particles starts when material is transferred via small areas of contact between the particles, after which time this contact area continuously increases ${ }^{31}$.

Figures 6(a) and (b) show SPS curves for cryomilled powders degassed at 250 and $350{ }^{\circ} \mathrm{C}$, respectively, in a tubular furnace under high vacuum. These curves did not show a degasification step and the vacuum remained at the 


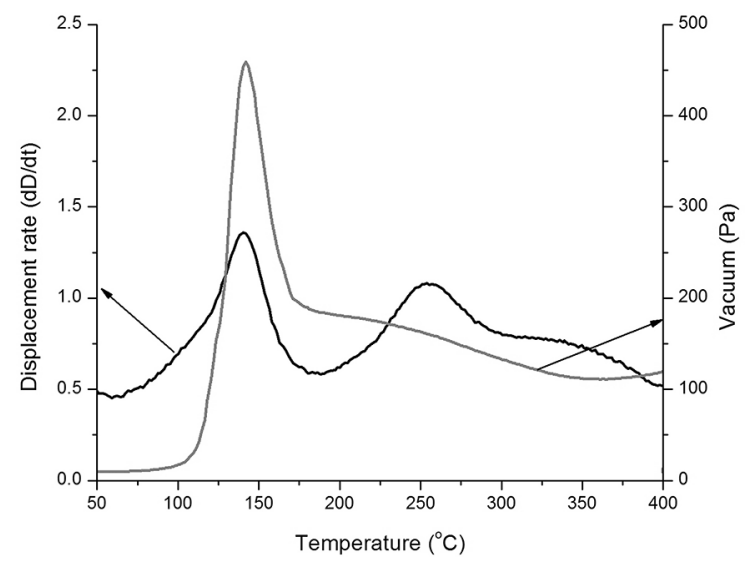

Figure 5. Sintering curves at $525^{\circ} \mathrm{C}$ and $60 \mathrm{MPa}$ of pressure for a non-degassed sample cryomilled for $8 \mathrm{~h}$

initial level over the whole cycle. Hence, it can be concluded that the gas adsorbed on the powder surface was removed during the degasification pre-treatment. This degasification process before sintering resulted in easier sintering and was essential for achieving high density and a desirable microstructure. The Archimedes densities of the sintered samples are shown in Table 3.

The atomized sample reached full density (>99.9), while the sample milled for $8 \mathrm{~h}$ without degassing only achieved a relatively low density of about $87 \%$. On the contrary, the samples that were both cryomilled and degassed approached full density, around $98 \%$.

\subsection{Microstructure and purity of the sintered samples}

Table 4 shows the concentration of nitrogen and oxygen impurities in the samples sintered using atomized and milled powders degassed at two different temperatures. The amount of impurities in both types of samples was low, while a high concentration of nitrogen and oxygen was found in the milled sintered sample because of the use of liquid nitrogen during milling.

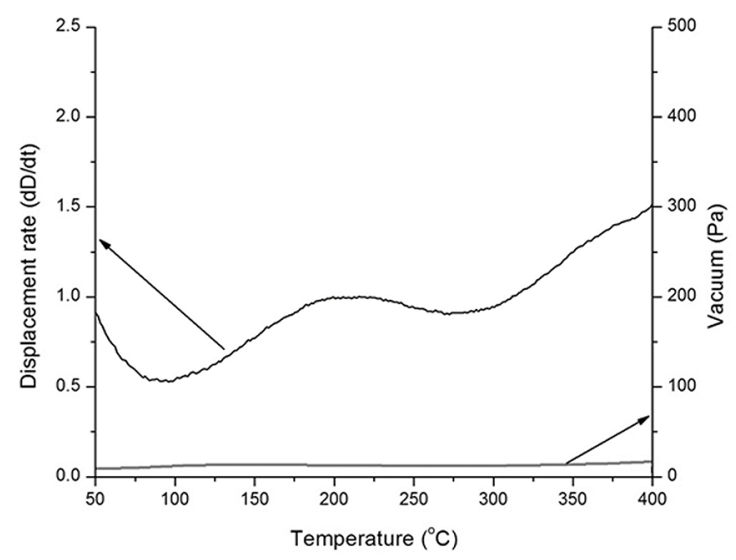

(a)
Table 3. Archimedes density of atomized and 8-h milled samples, sintered at $525^{\circ} \mathrm{C}$ under $60 \mathrm{MPa}$.

\begin{tabular}{lcc}
\hline & Degassing & $\begin{array}{c}\text { Archimedes } \\
\text { density (\%) }\end{array}$ \\
\hline Atomized & -- & $99.96 \pm 0.02$ \\
Milled $8 \mathrm{~h}$ & -- & $86.94 \pm 0.03$ \\
& $250^{\circ} \mathrm{C} / 20 \mathrm{~h}$ & $97.87 \pm 0.05$ \\
& $350^{\circ} \mathrm{C} / 20 \mathrm{~h}$ & $97.93 \pm 0.04$ \\
\hline
\end{tabular}

Table 4. Nitrogen and oxygen contents in atomized samples, milled for $8 \mathrm{~h}$ in cryogenic atmosphere and degassed.

\begin{tabular}{lccc}
\hline & Degassing & $\mathbf{N}_{\mathbf{2}}(\mathbf{\%})$ & $\mathbf{O}_{\mathbf{2}}(\mathbf{\%})$ \\
\hline Atomized & -- & 0.002 & 0.207 \\
& -- & 4.330 & 11.120 \\
\multirow{3}{*}{ Milled $8 \mathrm{~h}$} & $250^{\circ} \mathrm{C} / 20 \mathrm{~h}$ & 0.001 & 0.541 \\
& $350^{\circ} \mathrm{C} / 20 \mathrm{~h}$ & 0.002 & 0.220 \\
\hline
\end{tabular}

Figure 7 shows SEM images of the atomized and milled powders after sintering. The atomized sintered sample displayed equiaxial grains, several larger precipitates at the grain boundaries, and finer intragranular precipitates, as shown in Figure 7(a). The milled sintered sample showed residual micropores and precipitates, some of which were clustered; the grains were not visible due to the residual deformation, as shown in Figure 7(b). Figure 8 shows SEM micrographs of sintered samples after degasification. No differences were observed in the microstructures of samples sintered, milled, and degassed at different temperatures, as shown in Figure 8. Residual micropores and precipitates were still visible, as well as residual deformation.

Table 5 shows the hardness and microhardness values of the atomized and milled samples. Despite the grain growth that occurred during the degassing treatment, the hardness and the microhardness of the degassed sintered samples were higher than those of the atomized grains due to their finer structure.

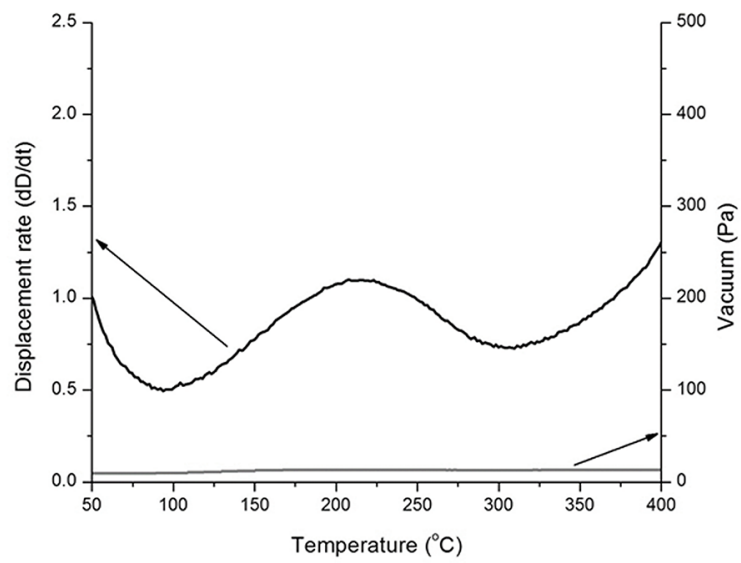

(b)

Figure 6. Sintering curves of the samples milled for $8 \mathrm{~h}$ and degassed for $20 \mathrm{~h}$ at (a) $250{ }^{\circ} \mathrm{C}$ and (b) $350{ }^{\circ} \mathrm{C}$ at $60 \mathrm{MPa}$ of pressure. 


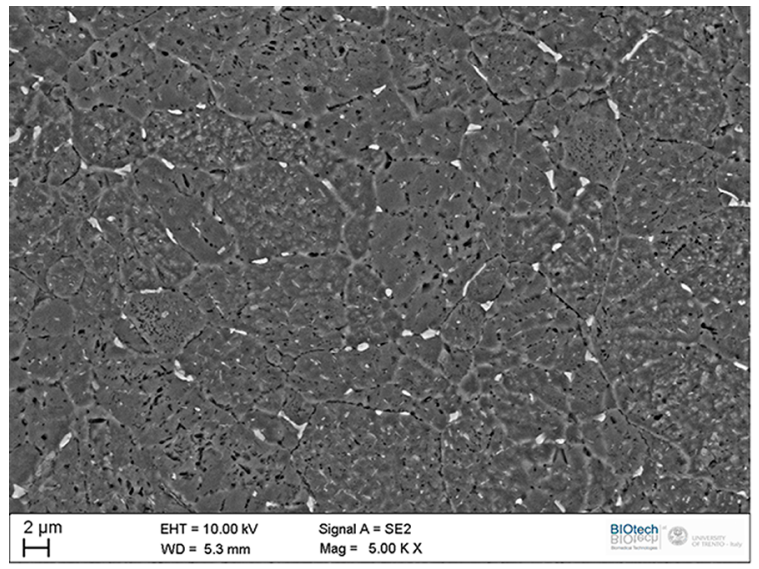

(a)

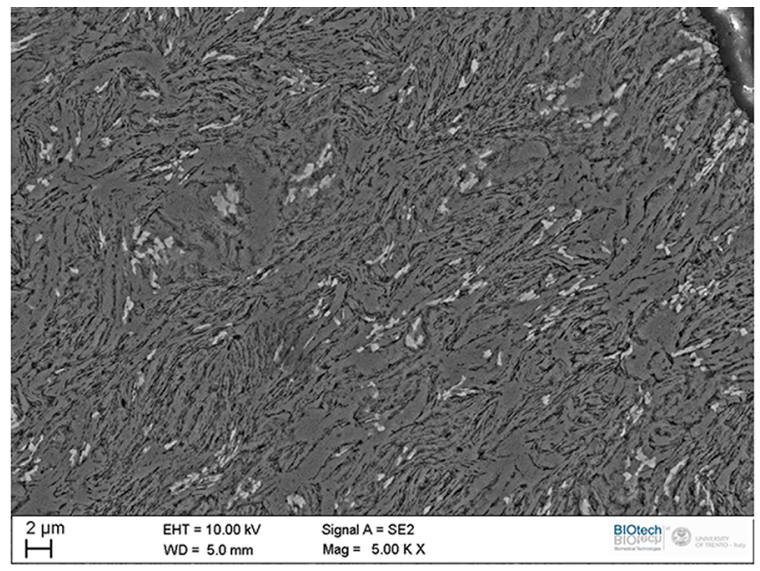

(b)

Figure 7. SEM images of (a) atomized and (b) $8 \mathrm{~h}$ milled samples after sintering.

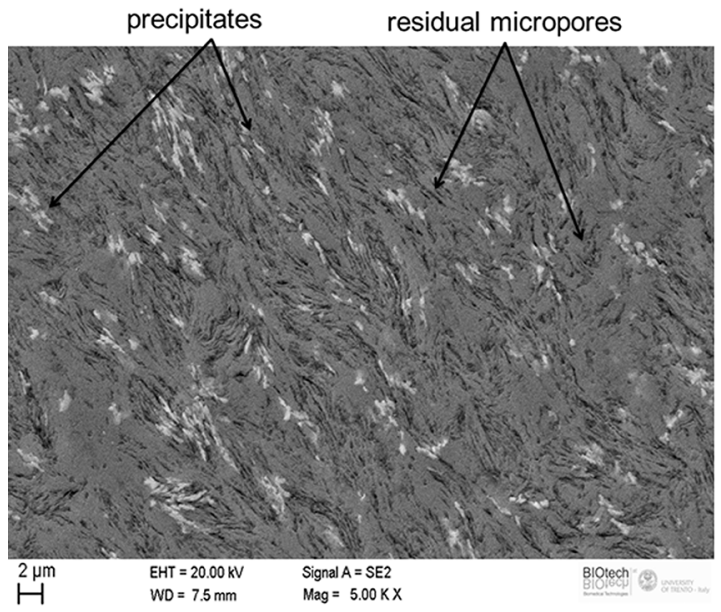

(a)

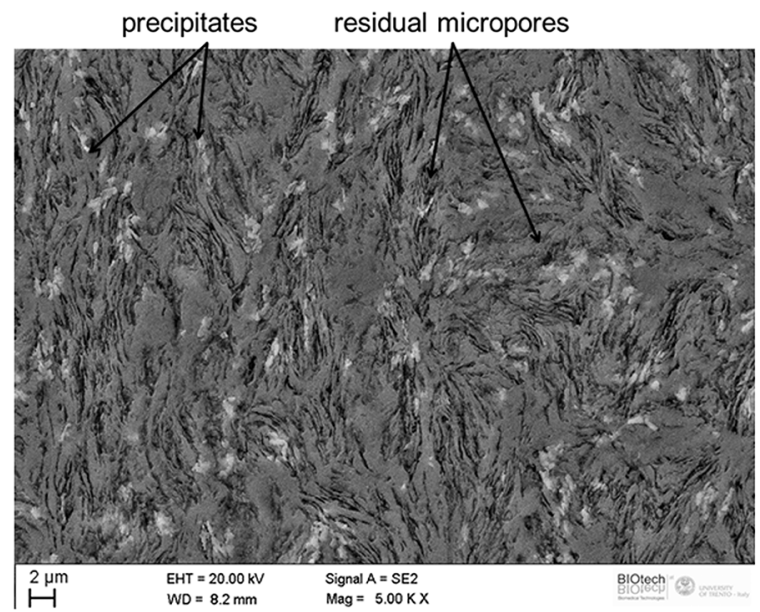

(b)

Figure 8. SEM images of samples cryomilled for $8 \mathrm{~h}$, degassed for $20 \mathrm{~h}$ at (a) $250{ }^{\circ} \mathrm{C}$ and (b) $350{ }^{\circ} \mathrm{C}$, and then sintered.

Table 5. Hardness and microhardness of the atomized and $8 \mathrm{~h}$ milled and sintered samples.

\begin{tabular}{lccc}
\hline & Degassing & $\begin{array}{c}\text { Hardness } \\
\text { (HB 62.5) }\end{array}$ & $\begin{array}{c}\text { Microhardness } \\
\text { (HV 0.05) }\end{array}$ \\
\hline Atomized & -- & $72 \pm 0.05$ & $118 \pm 3$ \\
& -- & $77 \pm 0.15$ & $133 \pm 4$ \\
Milled 8 h & $250{ }^{\circ} \mathrm{C} / 20 \mathrm{~h}$ & $83 \pm 0.09$ & $190 \pm 6$ \\
& $350^{\circ} \mathrm{C} / 20 \mathrm{~h}$ & $83 \pm 0.02$ & $188 \pm 5$ \\
\hline
\end{tabular}

TEM analyses were performed on the degassed sintered samples. The crystallites showed a bimodal size distribution with ultra-fine and micrometric zones, due to some grain growth during sintering. Such bimodal microstructures were also observed by Lee et al. ${ }^{12}$, who investigated SPS of copper particles subjected to single pulse discharges; they observed that sparks were formed only among some particles. Consequently, we propose that the bimodal distribution occurred due to local overheating caused by such sparks. Figure 9 shows TEM images, where ultra-fine zones without significant precipitation can be seen. The crystallites measured about 100 to $300 \mathrm{~nm}$ and the nanopores were generally distributed at the grains boundaries. There was no difference in the microstructures of the samples degassed at the two different temperatures. The micrometric zone contained precipitates distributed inside the grains (rounded $\theta$ phases and elongated $\mathrm{S}$ phases ${ }^{39}$ ), as shown in Figure 10. The precipitates measured around $20-200 \mathrm{~nm}$. The EDS microanalyses confirmed the chemical composition of the $\theta\left(\mathrm{Al}_{2} \mathrm{Cu}\right), \mathrm{S}\left(\mathrm{Al}_{2} \mathrm{CuMg}\right)$ phases and matrix, as shown in Figure 11 (a), (b), and (c), respectively. During the milling, the powder in contact with the liquid nitrogen formed some impurities, such as AIN; Figure 12 shows such AIN particles formed within the grains. As the microstructures of the samples degassed at 250 and $350{ }^{\circ} \mathrm{C}$ were similar, sample degassing at the lower temperature is preferred. 


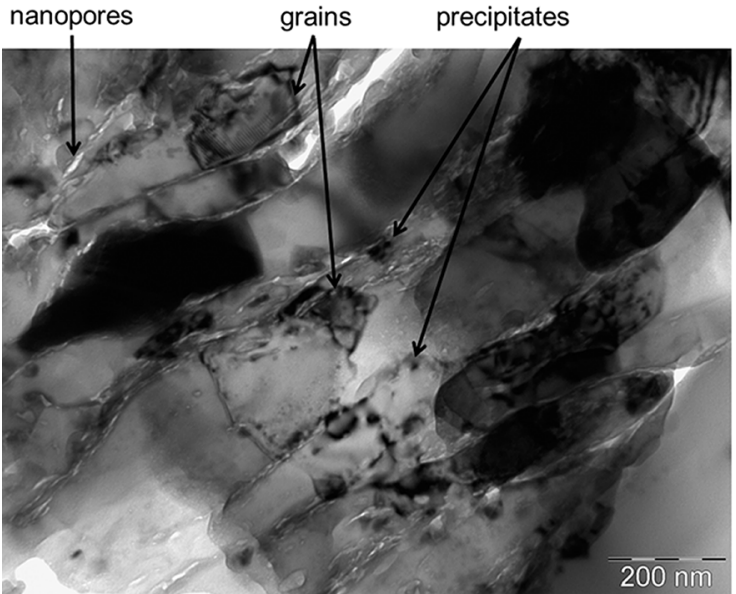

(a)

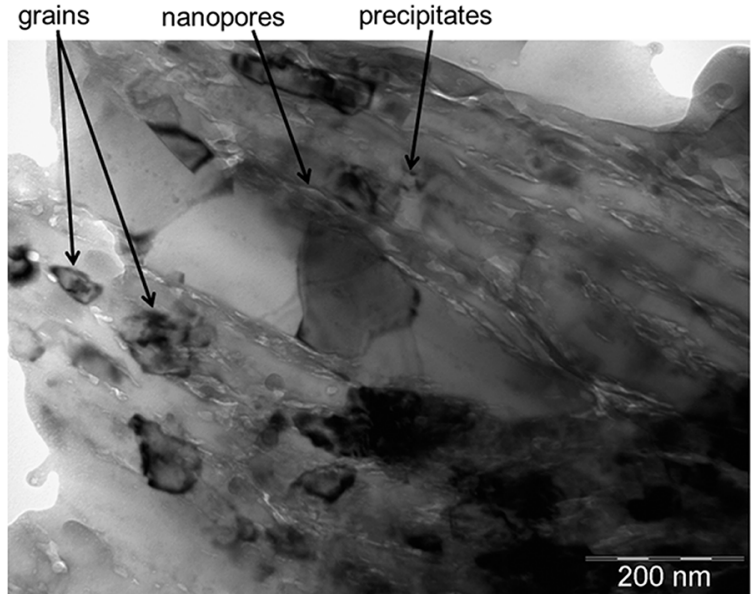

(b)

Figure 9. TEM images showing the microstructure of cryomilled sample degassed for $20 \mathrm{~h}$ at (a) $250{ }^{\circ} \mathrm{C}$ and (b) $350{ }^{\circ} \mathrm{C}$ and then sintered.

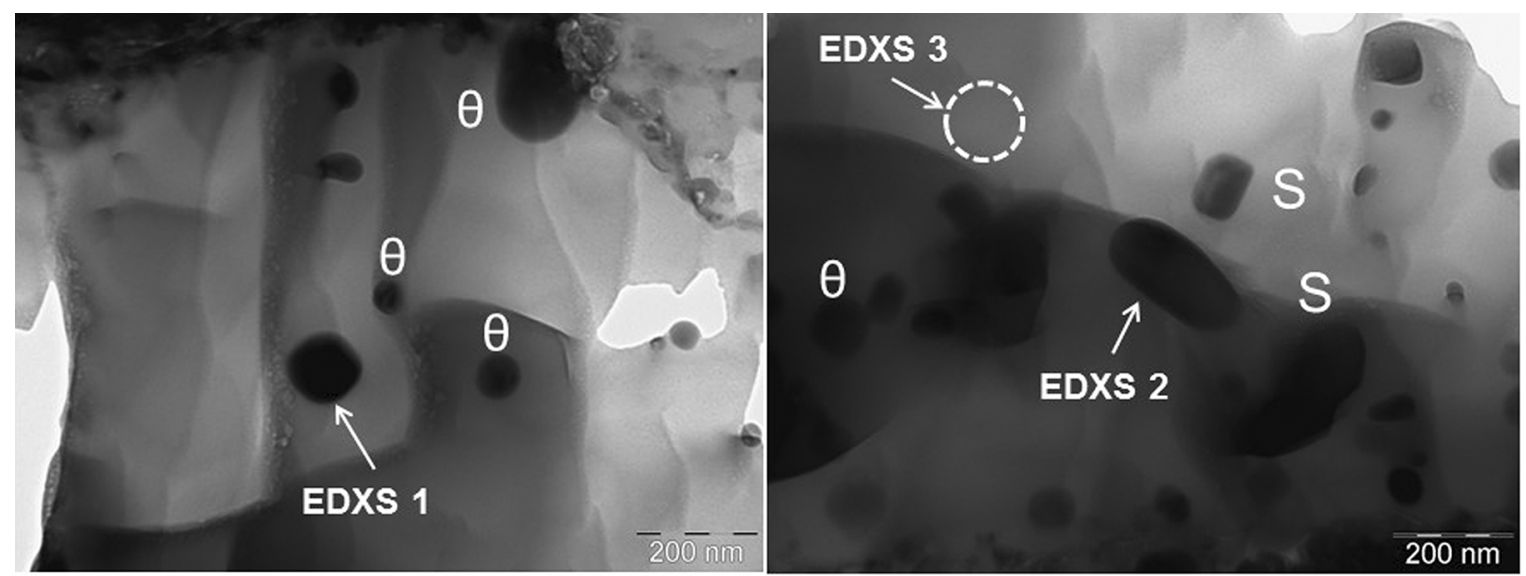

Figure 10. TEM analyses showing $\theta$ and $\mathrm{S}$ precipitates in the sample cryomilled for $8 \mathrm{~h}$, degassed at $250{ }^{\circ} \mathrm{C}$ for $20 \mathrm{~h}$, and then sintered.

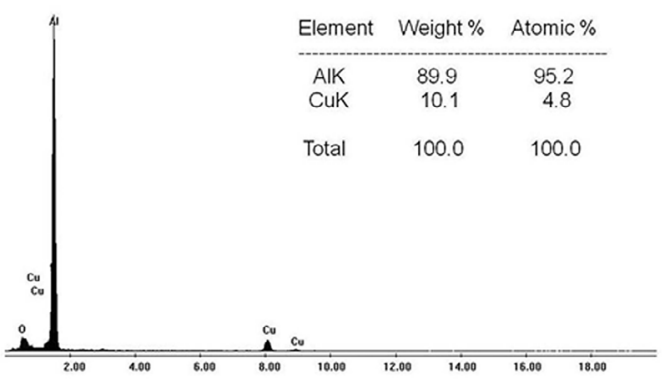

(a)

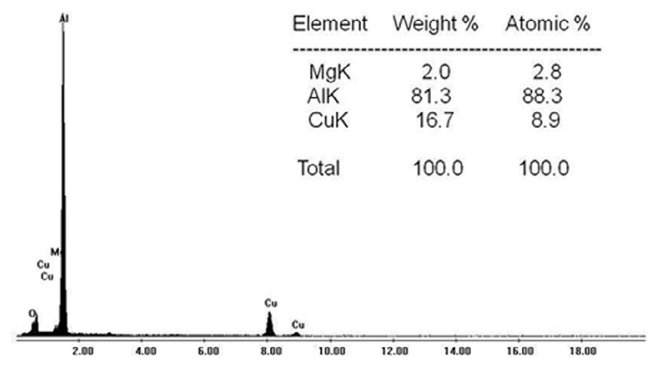

(b)

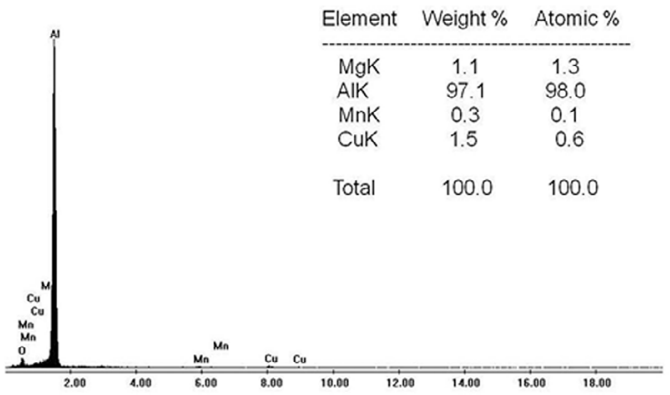

(c)

Figure 11. EDS microanalysis results verifying the chemical composition of the (a) $\theta$ and (b) S phases and (c) matrix. 


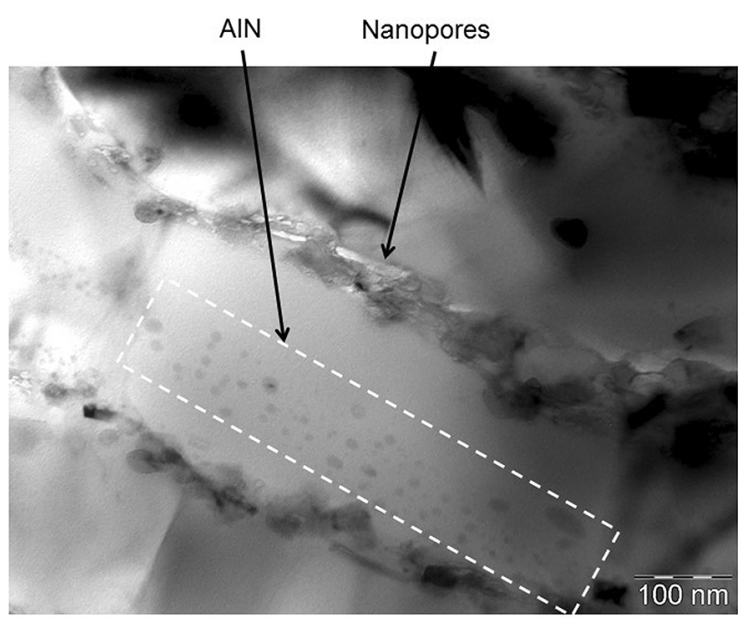

Figure 12. TEM image showing AIN and nanopores in the cryomilled sample degassed at $350^{\circ} \mathrm{C}$ for $20 \mathrm{~h}$. The sintering was carried out at $525^{\circ} \mathrm{C}$ and $60 \mathrm{MPa}$.

\section{Conclusion}

The thermal stability of powder milled under cryogenic conditions should be low due to the high microstrains introduced into the grains during the high-energy milling. The oxygen and nitrogen present during cryogenic milling was successfully eliminated by degasification for $20 \mathrm{~h}$ at 250 and $350{ }^{\circ} \mathrm{C}$. However, this degasification treatment promoted grain growth and the degassed powder showed a structure with grain sizes smaller than $100 \mathrm{~nm}$. UFG/ micrometric $2024 \mathrm{Al}$ alloy samples were produced by SPS at different temperatures. The milled samples reached total density with a high sintering temperature of $525^{\circ} \mathrm{C}$ and an applied pressure of $60 \mathrm{MPa}$. The densities were lower for cryomilled samples produced with non-degassed powders. Therefore, nearly total density ( $\sim 98 \%)$ was observed for degassed powders sintered at $525^{\circ} \mathrm{C}$ with $60 \mathrm{MPa}$ of applied pressure. The hardness and microhardness of the milled degassed sintered samples showed values superior to those of the atomized samples. The milled samples exhibited ultra-fine bimodal grain size distributions in the range of 100-300 $\mathrm{nm}$ (UFG) with micrometric zones. The material also contained nanopores in the grain boundaries, very fine precipitates of $\mathrm{AIN}$, rounded $\theta$ phases $\left(\mathrm{Al}_{2} \mathrm{Cu}\right)$, and elongated $\mathrm{S}$ phases $\left(\mathrm{Al}_{2} \mathrm{CuMg}\right)$. EDS microanalyses confirmed the stoichiometric composition of the matrix and these two precipitates. Grain growth did not occur during degasification and sintering and the material maintained a refined UFG/micrometric microstructure.

\section{References}

1. Lavernia EJ, Han BQ, Schoenung JM. Cryomilled nanostructured materials: Processing and properties. Materials Science and Engineering: A. 2008;493(1-2):207-214.
2. Witkin DB, Lavernia EJ. Synthesis and mechanical behavior of nanostructured materials via cryomilling. Progress in Materials Science. 2006;51(1):1-60.

3. Lewandowska M, Kurzydlowski KJ. Thermal stability of a nanostructured aluminium alloy. Materials Characterization. 2005;55(4-5):395-401.

4. Eckert J, Holzer JC, Krill CE, Johnson WL. Structural and thermodynamic properties of nanocrystalline fcc metals prepared by mechanical attrition. Journal of Materials Research. 1992;7(7):1751-1761.

5. Koch CC. The synthesis and structure of nanocrystalline materials produced by mechanical attrition: A review. Nanostructured Materials. 1993;2(2):109-129.

6. Choi JH, Moon KI, Kim JK, Oh YM, Suh JH, Kim SJ. Consolidation behavior of nanocrystalline Al-5at.\%Ti alloys synthesized by cryogenic milling. Journal of Alloys and Compounds. 2001;315(1-2):178-186.

7. Zhou F, Witkin D, Nutt SR, Lavernia EJ. Formation of nanostructure in $\mathrm{Al}$ produced by a low-energy ball milling at cryogenic temperature. Materials Science and Engineering. A. 2004;375-377:917-921.

8. Suryanarayana C. Mechanical alloying and milling. Progress in Materials Science. 2001;46(1-2):1-184.

9. Chatterjee S, Wang HS, Yang JR, Bhadeshia HKDH. Mechanical stabilisation of austenite. Materials Science Technology. 2006;22(6):641-644.

10. Moelle $\mathrm{CH}$, Fecht HJ. Thermal stability of nanocrystalline iron prepared by mechanical attrition. Nanostructured Materials. 1995;6(1-4):421-424.

11. Tschöpe A, Birringer R, Gleiter H. Calorimetric measurements of the thermal relaxation in nanocrystalline platinum. Journal of Applied Physics. 1992;71(11):5391-5394.

12. Lee Z, Witkin DB, Radmilovic V, Lavernia EJ, Nutt SR. Bimodal microstructure and deformation of cryomilled bulk nanocrystalline Al-7.5Mg alloy. Materials Science and Engineering: A. 2005;410-411:462-467.

13. Hayes R, Tellkamp V, Lavernia E. A preliminary creep study of a bulk nanocrystalline Al-Mg alloy. Scripta Materialia. 1999;41(7):743-748.

14. Brochu M, Zimmerly T, Ajdelsztajn L, Lavernia EJ, Kim G. Dynamic consolidation of nanostructured $\mathrm{Al}-7.5 \% \mathrm{Mg}$ alloy powders. Materials Science and Engineering: A. 2007;466(12):84-89.

15. Sulima I, Putyra P, Hyjek P, Tokarski T. Effect of SPS parameters on densification and properties of steel matrix composites. Advanced Powder Technology. 2015;26(4):1152-1161.

16. Hangai Y, Matsushita H, Koyama S, Suzuki R, Matsubara M. Reproducibility of Aluminum Foam by Combining Sintering and Dissolution Process with Precursor Foaming Process. Metallurgical and Materials Transactions A . 2017;48(7):31613163.

17. Kubota M. Properties of nano-structured pure Al produced by mechanical grinding and spark plasma sintering. Journal of Alloys and Compounds. 2007;434-435:294-297. 
18. Khor KA, Cheng KH, Yu LG, Boey F. Thermal conductivity and dielectric constant of spark plasma sintered aluminum nitride. Materials Science and Engineering: A. 2003;347(1-2):300-305.

19. Mondet M, Barraud E, Lemonnier S, Allain N, Grosdidier T. Optimisation of the mechanical properties of a Spark Plasma Sintered (SPS) magnesium alloy through a post-sintering insitu precipitation treatment. Journal of Alloys and Compounds. 2017;698:259-266.

20. Zarebski K, Putyra P. Iron powder-based graded products sintered by conventional method and by SPS. Advanced Powder Technology. 2015;26(2):401-408.

21. Zadra M, Casari F, Molinari A. Microstructure and Mechanical Properties of Nanostructured Aluminium Consolidated by SPS. Materials Science Forum. 2007;534-536:1401-1404.

22. Libardi S, Zadra M, Casari F, Molinari A. Mechanical properties of nanostructured and ultrafine-grained iron alloys produced by spark plasma sintering of ball milled powders. Materials Science and Engineering: A. 2008;478(1-2):243-250.

23. Hayes RW, Witkin D, Zhou F, Lavernia EJ. Deformation and activation volumes of cryomilled ultrafine-grained aluminum. Acta Materialia. 2004;52(14):4259-4271.

24. Witkin D, Lee Z, Rodriguez R, Nutt S, Lavernia E. Al-Mg alloy engineered with bimodal grain size for high strength and increased ductility. Scripta Materialia. 2003;49(4):297-302.

25. Rodriguez R, Hayes RW, Berbon PB, Lavernia EJ. Tensile and creep behavior of cryomilled Inco 625. Acta Materialia. 2003;51(4):911-929.

26. Cheng S, Zhao YH, Zhu YT, Ma E. Optimizing the strength and ductility of fine structured $2024 \mathrm{Al}$ alloy by nano-precipitation. Acta Materialia. 2007;55(15):5822-5832.

27. Jafari M, Enayati MH, Abbasi MH, Karimzadeh F. Thermal stability and structural changes during heat treatment of nanostructured Al2024 alloy. Journal of Alloys and Compounds. 2009; 478(1-2):260-264.

28. Chen LC, Spaepen F. Analysis of calorimetric measurements of grain growth, Journal of Applied Physics. Journal of Applied Physics. 1991;69(2):679-688.
29. Rajan JI, Panigrahi SK. Influence of Initial Microstructure on Microstructural Stability and Mechanical Behavior of Cryorolled A356 Alloy Subjected to Annealing. Metallurgical and Materials Transactions A. 2017;48(8):3852-3868.

30. Zhang H, Upmanyu M, Srolovitz DJ. Curvature driven grain boundary migration in aluminum: molecular dynamics simulations. Acta Materialia. 2005;53(1):79-86.

31. Lonardelli I. Deformation mechanisms in bulk nanostructured aluminum obtained after cryomilling and consolidation by spark plasma sintering. [Thesis]. Trento: University of Trento; 2010.

32. Zhao YH, Lu K, Zhang K. Microstructure evolution and thermal properties in nanocrystalline $\mathrm{Cu}$ during mechanical attrition. Physical Review B. 2002;66(8):085404.

33. Molinari A, Lonardelli I, Demetrio K, Menapace C. Effect of the particle size on the thermal stability of nanostructured aluminum powder: dislocation density and second-phase particles controlling the grain growth. Journal of Materials Science. 2010;45(24):6739-6746.

34. Badini C, Marino F, Verné E. Calorimetric study on precipitation path in 2024 alloy and its $\mathrm{SiC}$ composite. Materials Science and Engineering: A. 1995;191(1-2):185-191.

35. Murayama M, Horita Z, Hono K. Microstructure of two-phase $\mathrm{Al}-1.7 \mathrm{at} \% \mathrm{Cu}$ alloy deformed by equal-channel angular pressing. Acta Materialia. 2001;49(1):21-29.

36. Wang X, Wu G, Sun D, Jiang L, Han Y. Aging Behavior of High Volume Fraction SiC Particles Reinforced 2024 Al Composite. Journal of Materials Science \& Technology. 2004;20(2):167172.

37. Khitouni M, Daly R, Kolsi AW, Njah N. X-ray studies of structure defects in nanostructured $\mathrm{Al}-4 \mathrm{wt} \% \mathrm{Cu}$ alloy. Physical Status Solidi C. 2006;3(9):3341-3346.

38. Zhou F, Lee J, Dallek S, Lavernia EJ. High grain size stability of nanocrystalline Al prepared by mechanical attrition. Journal of Materials Research. 2001;16(12):3451-3458.

39. Ebrahimi GR, Zarei-Hanzaki A, Haghshenas M, Arabshahi $\mathrm{H}$. The effect of heat treatment on hot deformation behaviour of Al 2024. Journal of Materials Processing Technology. 2008;206(1-3):25-29. 